\title{
Frailty and risk
}

\author{
Glenn Arendts ${ }^{1}[$
}

Received: 21 March 2019 / Accepted: 28 August 2019 / Published online: 7 September 2019

(c) Springer Nature Switzerland AG 2019

\section{Dear Editor,}

We appreciate the thoughtful commentary by Dr. Cesari [1] on our research paper exploring 28-day reattendance prediction tools after emergency department (ED) discharge [2]. We agree with Dr Cesari regarding the counterintuitive nature of the results. However, we are no longer surprised by discovering ED discharge prediction instruments are less than ideal. Decades of research have still failed to identify a tool that has sufficient performance metrics for routine clinical use [3].

The original nomogram we developed was based on testing each variable in a non-summative fashion [4]. It yielded predictive variables that in themselves are most likely composite measures of vulnerability, e.g. polypharmacy, the need for allied health facilitation of discharge. In our latest paper, we tested the effects of summing those variables not significant in the original nomogram into ordinal measures of frailty and comorbidity. We believe the non-contribution of frailty has three possible explanations. First, that whatever contribution frailty made to reattendance risk was already captured by the existing nomogram. Second, as Dr. Cesari argues, that the methodology we chose was too crude to capture its contribution. Or third, that the relationship between advancing frailty and reattendance is not a simple correlation. This is not impossible and in fact was the exact relationship we found between reattendance and cognitive impairment - the risk for those with no impairment and severe impairment were both lower than for those with moderate impairment. It may be that the high vulnerability of those with advanced frailty has already been recognised and protective community supports are in place for them, whereas those with less severe frailty are "slipping through the cracks".

Glenn Arendts $\mathrm{PhD}$ on behalf of the co-authors.

\section{Compliance with ethical standards}

Conflict of interest I declare no conflicts of interest.

Ethical approval This letter reports no participant data or original research findings that require ethics approval.

Informed consent For this type of study formal consent is not required.

\section{References}

1. Cesari M (2019) There is much more than just diseases that underlies frailty in older persons. Aging Clin Exp Res. https:// doi.org/10.1007/s40520-019-01221-7

2. Gips E, Spilsbury K, Boecker C, Ng R, Arendts G (2018) Do frailty and comorbidity indices improve risk prediction of 28-day ED reattendance? Reanalysis of an ED discharge nomogram for older people. Aging Clin Exp Res 1:5-9

3. Carpenter CR, Shelton E, Fowler S et al (2015) Risk factors and screening instruments to predict adverse outcomes for undifferentiated older emergency department patients: a systematic review and meta-analysis. Acad Emerg Med 22:1-21

4. Arendts G, Fitzhardinge S, Pronk K, Hutton M, Nagree Y, Donaldson M (2013) Derivation of a nomogram to estimate probability of revisit in at-risk older adults discharged from the emergency department. Intern Emerg Med 8:249-254

Publisher's Note Springer Nature remains neutral with regard to jurisdictional claims in published maps and institutional affiliations.
Glenn Arendts

glenn.arendts@uwa.edu.au

1 School of Medicine, University of Western Australia, 9 Stirling Highway, Crawley, WA 6008, Australia 